\title{
Recording of Chewing louse Philopterus sp. (Mallophaga : Ischnocera) from Crow in Iraq
}

\author{
Zohair I. Rahemo \\ Fulk A. Al-Dabbagh \\ Department of Biology \\ College of Science \\ Mosul University
}

(Received 19/1/2009; Accepted 4/5/2009)

\begin{abstract}
Several specimens of lice were collected from the skin and feathers of the crow (Corvus sp.), and it is concluded that it belongs to Philopterus sp. (Mallophaga: Ischnocera). The body is small $2-3 \mathrm{~mm}$ in length and $0.8 \mathrm{~mm}$ in width, and is elongated, flattened tough and well chitinized. Head is triangular in shape expanded behind the eyes. Antennae are capitate lie anterior to maxillary pulp which is 4 - 5 segmented. Mouth with clear buccal capsule and provided with 3 pairs of spines at the sides of its head. Legs are short, with tibia leading to tarsus ending with a stout single claw. The ovipositor is clearly seen, in addition to crescent - shaped spermatheca. Such lice with these characters were not reported before from Iraqi birds, and it is concluded that it is very close to Philopterus sp. but species can't be determined in the absence of male specimens.
\end{abstract}

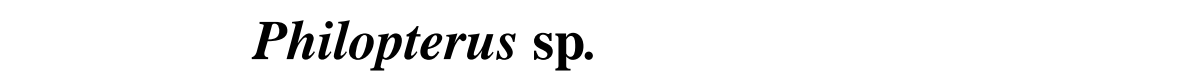

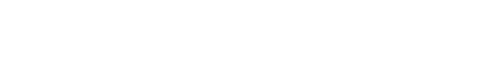

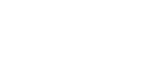

جمع العديد aن عينت القمل من جلد و ريث الغراب اللسود (Corvus sp) ، ولستنتج بانه L تتع -ود

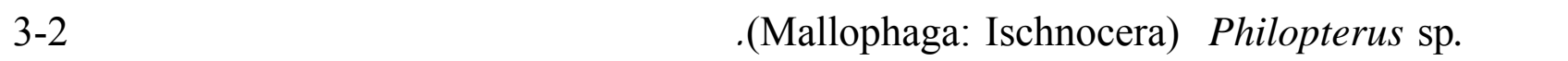

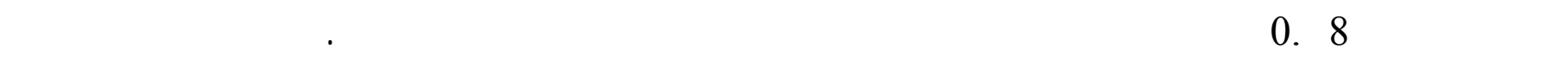

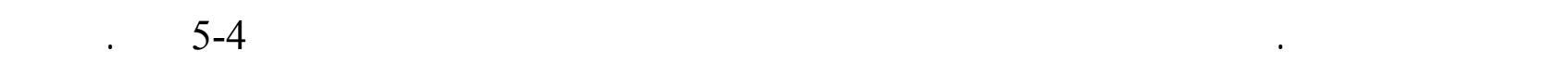

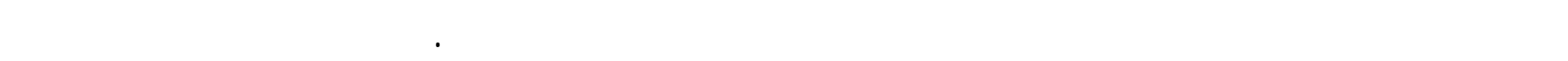

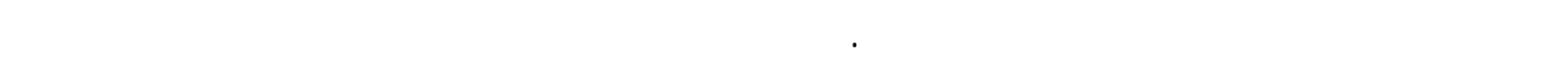

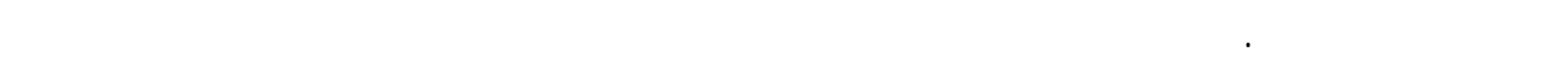

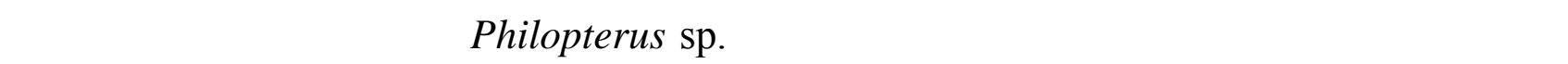

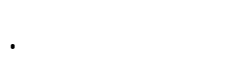




\section{INTRODUCTION}

Askew (1971) reviewed the parasitic insects and devoted a chapter to lice of birds and mammals. The parasitic lice are assigned to the orders : Mallophaga and Anoplura . Mallophaga and Anoplura are similar in many ways and the main difference between them is the structure of the mouth parts (Borror et al., 1981). Mallophaga in turn divided into three suborders according Askew (1971) namely Amblycerca, Ischnocera and Rhyncophthira. More generally Clayton and Moore (1996) gave an elaborated avian model of host - parasite evolution .

Smith (2000) wrote a valuable thesis on avian lice especially cladistic phylogeny based on morphology from suborders :

- Ischnocera, Comparative anatomy based on adult and Nymphal-instar morphology is used to explore both classical and novel homology hypothesis for a variety of characters system including chaetotaxy, head shape, preantennae morphology and internal genitalia .

- Nolan (2003) in his book give some details about bird lice .

- Recently Banks and Paterson (2004) studied the penguin chewing louse (Insecta: Phthiraptera) phylogeny derived from morphology penguins are found to be parasitized by 15 species of lice in the genera Austrogoniodes and Nesiotinus and presents an opportunity to analyze phylogenetic relationship of the two genera of chewing lice parasitizing a monophyletic group of hosts.

In Turkey mallophagan lice, Strigiphilus strigis was collected from Eurasian eagle owl Bubo bubo, and considered the first detection in Turkey (Dik and Uslu, 2007).The aim of present study is searching about external parasites of the local birds caught in Mosul city.

\section{MATERIALS AND METHODS}

During a project of investigation animal parasites (2000 - 2004) ten crows (Corvus sp.) were collected from Mosl city during spring season and brought to our labrotary for searching about external parasite (Lice) on their skin and feather, after keeping then in plastic sacs with cotton imprignated with chlorofrom, then lice were droped down in the plastic container. A total of 27 female lice were found and fixed in $10 \%$ formalin . Most of these specimens were dehydrated, cleared and mounted in canada Balsam. Measurment of different body parts of those mounted specimens were performed by using occular micrometer $7 \mathrm{x}$ after calibration the microscope by the using of stage micrometer at different magnification $100 \mathrm{x}-1000 \mathrm{x}$, the microscope used here is Altay type and the unit of measurment is millimeter $(\mathrm{mm})$.

\section{RESULTS AND DISCUSSION}

They are small apterus (wingless) ectoparasitic insects, brown to black in colour measured a bout $2-3 \mathrm{~mm}$ in length and $0.8-0.9 \mathrm{~mm}$ in width. Head is triangular in shape, measured a bout $0.2-0.3 \mathrm{~mm}$ in length and $0.7-0.8 \mathrm{~mm}$ in width, expanded behind the eyes (fig 1-3). It has clear bussal capsule which have three pairs of very prominent lateral sensory hairs (fig .3). Four-segmented antennae with last spatulated segment lie anterior to maxillary palps.

Mouth parts of biting type, two maxillary palps are presents at both sides of the head with 4-5 segements. The compound eyes are reduced, ocelli absent. Body is broad, flattened 
dorsally, tough and well chitinized thorax consist of three known segmets (prothoranomsotheraz and metathorax). Walking legs short with tibia leading to tarsus ending in a stout single claw opposite of which there are 2-3 sensory hairs (fig.5).

The abdomen has 8 clear abdominal segments, the anterior segment are fused with the thorax so that the last two thoracic legs are attached more close to the abdomen while the anterior pair in the "neck" region more close to the base of the head. Each of the abdominal segment bear three prominent sensory spines at its margin (fig. 1,2). The ovipositor is clearly seen at the level of the beginning of the fourth abdominal segments, the ovipositer leading to the vagina, and a crescent - shaped spermatheca were evident (fig. 1). Ovary and oviduct are not seen . Anal aperture at the last segment of abdomin (fig. 2,5,6).

The present species of lice does not be similar to any species of lice collected from chicken and pigeons of Baghdad governorate investigated by Abul - hab (1975), also not similar to the species reported on chickens in Mosul governorate such Cuclotogaster heterographits , Goniocotes gallinoe and other species studied in details by Al - Hubaity and Al-Habib (1979).

Al - Taqi (1975) recorded 29 species of the ectoparasitic lice of birds and animals in Kuwait, among members of family Philometridae, one species is recorded namely Columbicolar columbae L. from pigeon Columba livla from Kestrel, Falco timnuncitlits. This species is completely different from the present species .

By comparing the present species to those described and illustrated by Askew (1971), it appears that it is close to the species of Philopterus ocellatits except some differences in antennal shape which is clavate while those of the present species is capitate .

However, Askew (1971) reported four species namely, P. atratus collected from rook, $P$. carvi from raven, $P$. ocellatus from carrion crow and $P$. gitttatits from jackdaw. The present speaes is slightly similar to that discovered in Turkey, but vampute componison canot made becaues of the lack of male speimens. Anyhow, species of the present lice cannot be determined in the absence of male characters. 


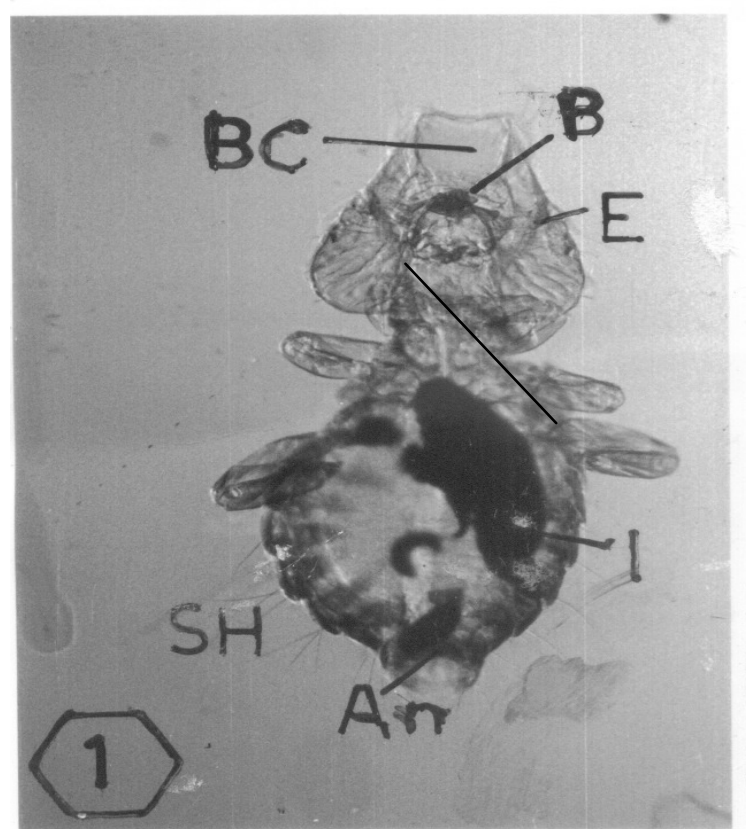

Fig.1: Photomicrograph of Philopterus sp. showing the general body shape and specially the buccal capsule $(\mathrm{BC})$, reduced eyes $(\mathrm{E})$, brain ganglion $(\mathrm{B})$, intestine (I), anus (An), and sensory hair (SH), Spermatheca (SP). Unstained specimen (40X) .

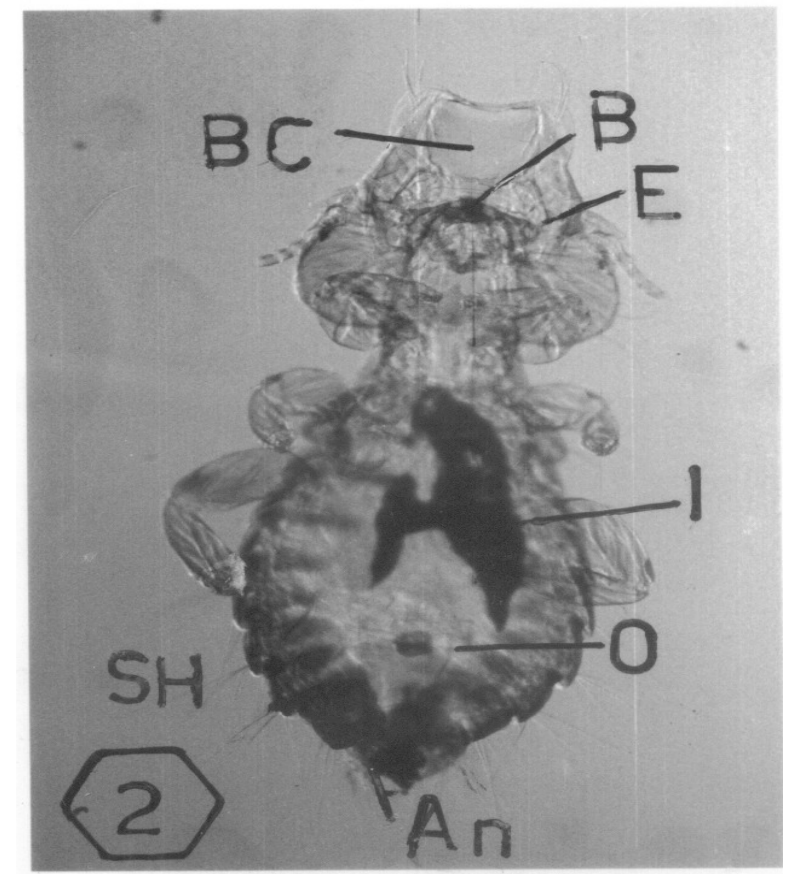

Fig. 2: Photomicrograph of Philopterns sp . showing the general body shape and especially buccal capsule (BC), brain (B), eye (E), intestine (I), Sensory hairs (SH), ovipositer (O), and anus (A). Unstained specimen (40X). 


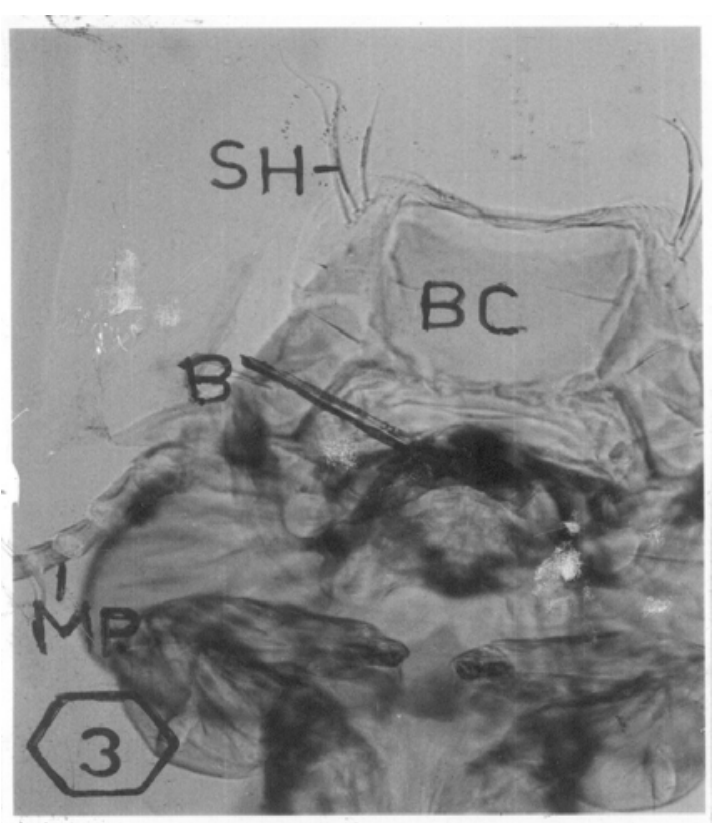

Fig. (3): Photomicrograph of Philopterus sp. anterior region showing the mouth parts espicially buccal capsules BC, sensory hair sit maxillary palp (MP), brain (B), Unstained specimen (100X)

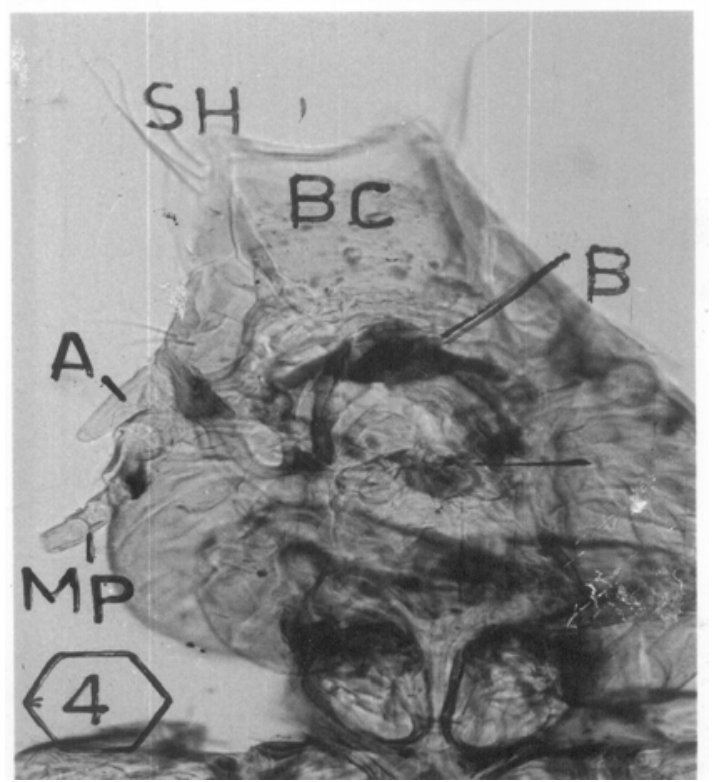

Fig. (4): An enlarged Photomicrograph of the head of Philopterus showing the clear buccal capsule (BC), sensory hairs (SH), ; Antenna (A) and maxillary palp (MP), brain (B). Unstained specimen (100X) . 


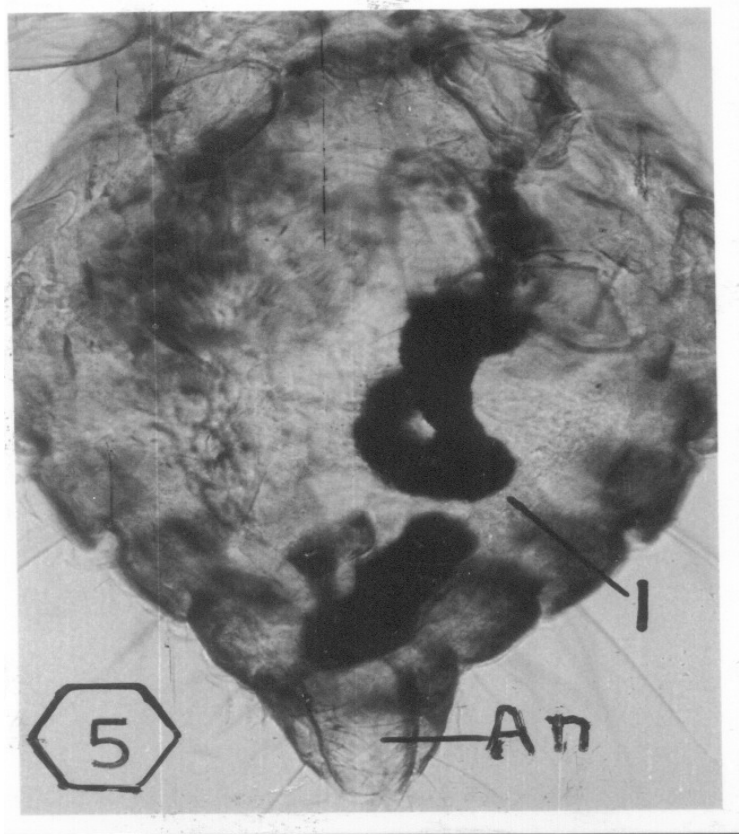

Fig. (5): An enlarged Photomicrograph of the posterior end of Philopterus sp. showing the posterior abdominal segments, intestine (I), open anus (An), Unstained specimen $(100 \mathrm{X})$.

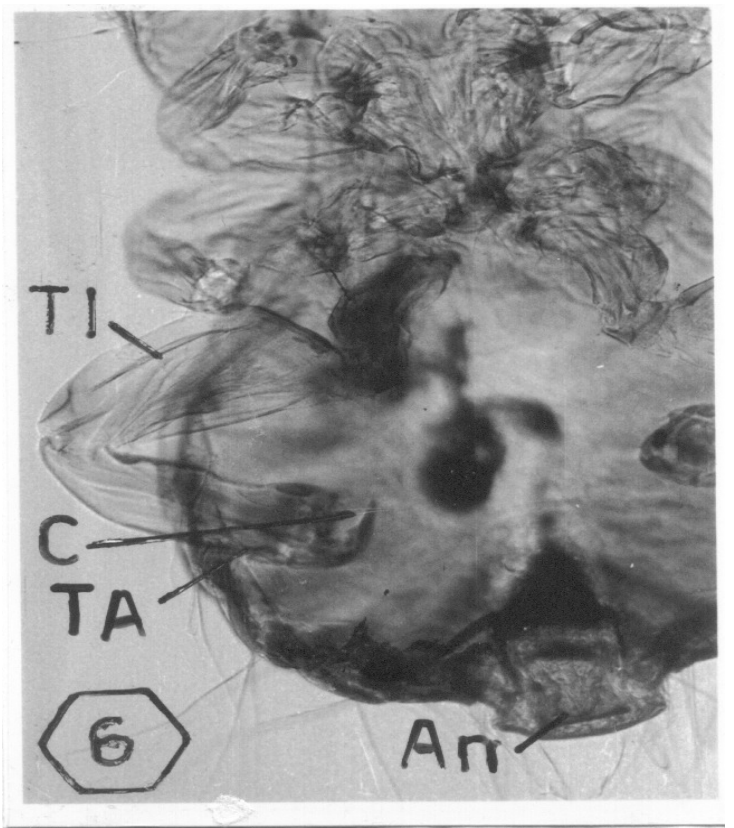

Fig. (6): An enlarged Photomicrograph of the posterior end of Philopterus sp. showing closed anal opening (An) and the posterior pair of legs showing the tibia (T1) tarsus (TA) and the claw (C), opposite small sensory hairs . Unstained specimen $(100 \mathrm{X})$. 


\section{REFERENCES}

Abul-hab, J.(1975). Biting lice of chickens and pigeons in baghdad area . Bulletin of the Biological Research Center publ. No. 4,1- 36.

Al-Hubaity, I. A. and Al-Habib, W. M.( 1979). A Survey of the helminthes parasites of the domestic fowl (Gallus gallus domesticus) in Mosul, District, Iraq. Mesopotamia . J. Agriculture 14 (1) , 197-205.

Al-Taqi, M.( 1975). A General Survey of Blood Protozoa and Ectoparasites of some Land Vertebrates in Kuwait. M. Sc. Thesis, University of Kuwait.

Askew, R. R.( 1971). "Parasitic Insects" . Heinemann Educational Books . London.

Banks, J. C. ; Paterson, A. M.( 2004). A penguin - chewing louse (Insecta : phthiraptera) phylogeny derived from morphology . Invertebrate Systematics. 18 (1), 89 100.

Borror, D. ; De Long, D. ; Triplehorn, C.( 1981) ." An Introduction to the Study of Insects" . fifth edn. Saunders college publishing .

Dik, B. ; Uslu, U.( 2007). Strigiphikus Strigis (Mallophaga:Philopteridac) in a Eurasiar Eagle Owl (Bub buo interpositus) in Turkey. Acta Parasitological Turkey. 31 (1), 69-71.

Clyton, D. H. ; Moore, J.( 1996). "Host-Parasite Evolution : General Principles and Avian Models" . Oxford University Press .

Nolan, T.( 2003). Veterinary Parasitology . VPTH 603 . Laboratory . 9 , Insects .

Smith, V. S.( 2000). Avian Louse (Phylogeny ( Phthiraptera : Ischnocera) : A Cladistic Study Based on Morphology. Unpublished Ph. D. Thesis . 